\title{
Fluency Strategies For Beginning Readers
}

\author{
Enid Acosta-Tello, National University, USA
}

\begin{abstract}
Fluency in reading is crucial for comprehension of the written word. Traditionally we concentrate on fluency once a child is a proficient reader. However, fluency is a skill that can be successfully addressed with beginning readers. This article presents practical strategies to help beginning readers become fluent readers. Of course, these strategies are effective with proficient readers, however, the earlier we begin to use them, the sooner children will internalize the concept of fluency and practice it. These strategies are also effective with second language learners.
\end{abstract}

Keywords: Fluency; Strategies; Beginning Readers

\section{INTRODUCTION}

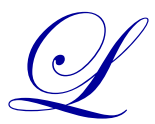
earning to read is one of the most challenging tasks we accomplish. While other tasks we learn such as walking, talking, and eating on our own come naturally and are essential to our everyday physical development, learning to read is a skill which is required of us, yet is foreign to our customary growth. Today's society, however, is a literate society, dependent on the written word. Therefore, a person who is unable to read fluently is at a disadvantage, one which severely impacts his life. While most children receive instruction in decoding, in unlocking the connection between what is spoken and what is written, in 1999 the United States (US) Department of Education reported that $71 \%$ of students in fourth grade were not proficient readers (U.S. Department of Education, 1999). In 2013, the Annie E. Casey Foundation's “Kids Count Data Book" reported that 66\% of fourth graders were not proficiently reading material written for them at their grade (The Annie E. Casey Foundation, 2015).

\section{HISTORICAL BACKGROUND}

Long recognized as a component skill of reading, fluency was considered to occur automatically as children practiced their reading. Early reading instruction in the US was characterized by the use of spellers in which children were expected to learn to spell a word before they could read it, syllabaries in which they practiced reading and memorizing syllables, and elocution in which children were required to read aloud, memorize stories, and recite them to demonstrate reading proficiency (Rogers, 2001; Wolf, 2017). Fluency was expected to "happen" as the child read more and learned the more complex aspects of reading. The crucial position that fluency holds today as related to comprehension was not recognized until the National Reading Panel listed it as one of the skills vital for becoming a successful reader, along with phonemic awareness, phonics, vocabulary, and comprehension (National Institute of Child Health and Human Development, 2000).

\section{THE IMPORTANCE OF FLUENCY}

At its most basic level, reading fluency is the ability to read accurately and with sufficient speed, allowing you not only to decipher the word, but be able to understand what the word itself means and how it relates to the whole passage. Without fluency, children are basically decoders, word callers who are able to decipher what the letters in the word say, letter by letter, or syllable by syllable, and who can then, hopefully, recognize what the word means individually; however, they are unable to understand how the word is related to and/or influences the words they read previously because of the amount of time it took to read a single word. Without fluency, comprehension is at the most minimal level compromised and at its furthest ramification unattainable.

Traditionally, children are expected to learn to read in first through third grades, acquiring all the skills related to the different letter combinations, consonants, digraphs, diphthongs, vowels and their differing sounds dependent on the position within the word and syllable. Then in fourth grade and above they are expected to use these skills to read 
textbooks on science and history and math, understand what they read, and be able to use and apply this knowledge. As data cited above indicates, this is not possible because most children are not proficient readers in fourth grade. Without fluency, children are unable to read those textbooks and understand and learn from them. Fluency, therefore, is crucial, and there is a growing realization that fluency must be attended to much earlier than third or even second grade (Bashir \& Hook, 2009; Miller \& Schwanenflugel, 2008; Rasinski, 2014; Schwanenflugel, Meisinger, Wisenbaker, Kuhn, Strauss \& Morris, 2006).

Based on extensive experience as a teacher of record, reading specialist, principal, and an observant researcher, the author suggests that as soon as children 1) are phonemically aware, 2) make the connection between spoken sounds and their written symbols, and 3) acquire the concept of blending letters to make readable words, then children should participate in fluency activities. Reading is a developmental process, so this convergence of literacy understandings and knowledge occurs at different times for children depending heavily on their access to early schooling and their experiences with books at home. Therefore, the timing for the incorporation and frequency of fluency activities into classroom instruction relies on the teacher's observation of student reading progress.

\section{FLUENCY STRATEGIES}

The following strategies represent a few fluency activities which may be used with beginning readers in order to highlight the concept of automaticity. Automaticity is the expectation that once a child can decode (read) a word, they should be able to read it automatically upon seeing it. This ability frees both their short-term memory and working memory to focus on comprehension rather than on decoding.

\section{Double Time Word Lists}

The objective of the "Double Time Word Lists" is for children to read words quickly from a list without decoding them. Double Time Lists are lists of single words sorted by levels of difficulty (such as Dolch words) written on a chart in column format. Children read the lists as a group, reading each word twice. This double reading allows the child who does not know the word the opportunity to listen while the word is read the first time by those who know it, and then to read it with the group the second time it is read aloud. The individual words are also discussed separately, providing the opportunity for the children to learn the meaning of the words before encountering them in their books. These lists should be read daily, if only for five or ten minutes, and the children can be encouraged to read the lists "quicker today than they did yesterday," challenging themselves to read faster. These "Double Time Lists" can also be converted into "Individual Student Double Time Lists" which children can have at their desks or take home for practice.

\section{Flash Cards}

The objective in using "old fashioned flash cards" is to expose the students repeatedly to the words so they get accustomed to seeing them and can read them automatically without decoding. If a blank card is included in the pack, then the child can use this card to record when he read the words with a buddy or a parent and can indicate how many words he read correctly. Once the child has studied the cards for a specified length of time or has achieved a predetermined level of mastery, the child makes an appointment with the teacher to read through the cards so the teacher can identify which words are mastered. These are then replaced with new words and the words which are mastered are moved to "Word Banks."

\section{Word Banks}

Flash cards that are mastered are moved to a child's "Word Bank." The objective of the "Word Banks" is to show the student the number of words they have learned and to continue to practice reading them and using them in everyday writing. A Word Bank can be as simple as a white envelope which the child decorates or as fancy as boxes small enough to fit into the child's desk. Word Bank words need to be re-read on a regular basis (once a month or a grading period) with a child in a higher group, an upper-grade friend, or a parent. Word Bank words not recognized on sight need to be returned to the flash card pile. Children should be encouraged to use the words in the Word Banks when they write. They can also practice alphabetization skills once a large enough set of words is in the Bank. 


\section{Words in a Box}

The objective of "Words in a Box" is to reinforce the idea that once a child has decoded a word, he should then learn to read it "on sight," automatically. Words in a Box is a small group activity. For this task, write words on slips of paper and then deposit them into a box large enough so children can reach in and retrieve one of the words. These can be words taken from the Double Time Word Lists or the books the children are reading. The children then take turns pulling one slip of paper out of the box. After setting a timer, the teacher begins, asking one child to read his word aloud correctly, without "sounding it out." If the child needs to decode a word, then he is encouraged to "decode in his head." If the child reads the word correctly and fluently, he receives a point and can pick another word from the box. If the child hesitates or begins to decode aloud, the teacher should allow him more time and proceed to the next child, reminding him to "sound it out" in his head. If the child is unable to read the word the next time around, the teacher is to say the word for him and let him choose a different word. He does not get a point for that word and the unread word is returned to the box - perhaps the child may choose that same word the next time! When the timer goes off, the children celebrate how many points they received, noting if they read more words this time than the last time they played.

\section{Phrases in a Box / Sentences in a Box}

These are both variations of "Words in a Box" except that either phrases or complete sentences are used.

\section{Choral Reading}

Choral Reading is an activity in which children read aloud in unison from a chart, either with the whole class or in a small group. Though choral reading is appropriate at any grade, when used with beginning readers, the use of familiar poems, nursery rhymes, or even songs which the children already know is recommended. If songs are used, the children are not to sing the song, but to read it aloud. Reading the words of the song provides a foundation from which to practice fluency since the children already know some of the words from having sung them and can then match the words they speak to the words written on the chart.

\section{Radio Reading/TV Reading}

In this fluency activity, children are informed that announcers on the radio and reporters on TV do not just talk about the news, they read a script. Children are then encouraged to write their own news stories (these could center around class activities, school, community or even world events) which they then read aloud during a structured time during the week.

\section{Writing Your Own Commercial}

Children hear commercials all the time. Children are encouraged to write commercials of their own about a favorite toy, food, or place and then read them aloud fluently to the class. These can be video-recorded and shared with others.

\section{CONCLUSION}

This paper presented strategies which can be used with beginning readers to impress them with the importance of reading fluently. It also provided practical activities with which to engage the children to help them practice reading words repeatedly so they are able to progress from decoding to automaticity. Fluency is a vital skill which children need to develop to enhance their comprehension of written content and engage in meaningful thinking tasks.

\section{AUTHOR BIOGRAPHIY}

Dr. Enid Acosta-Tello was a classroom teacher, bilingual teacher, reading specialist and administrator for over 30 years before joining the teacher education departments of several universities, including California State University, Fullerton, University of California, Irvine, and Chapman University. As teacher, she excelled at teaching all her students to read and, as principal, teaching others to do the same. Now a Professor at National University, she 
continues to study the brain's ability to learn to read, why some children are more proficient at reading than others, and to inspire teachers to engage children in learning with passion and vision. Email: eacostat@nu.edu

\section{REFERENCES}

Bashir, A. \& Hook, P. (2009). Fluency: A key link between word identification and comprehension. Language, Speech \& Hearing Services in Schools 40 (2). 0161-1461/09/4002-0196

Miller, J. \& Schwanenflugel, P. (2008). A longitudinal study of the development of reading prosody as a dimension of oral reading fluency in early elementary school children. Reading Research Quarterly, 43 (4), 336-354. dx.doi.org/10.1598/RRQ.43.4.2

National Institute of Child Health and Human Development. (2000). Report of the National Reading Panel. Retrieved from https://www.nichd.nih.gov/publications/pubs/nrp/pages/findings.aspx

Rasinski, T. (2014). Fluency matters. International Electronic Journal of Elementary Education, 7 (1), 3-12.

Rodgers, G. (2001). The History of Beginning Reading. Bloomington, IN: AuthorHouse.

Schwanenflugel, P., Meisinger, E., Wisenbaker, J., Kuhn, M., Strauss, G., \& Morris, R. (2006). Becoming a fluent and automatic reader in the early elementary school years. Reading Research Quarterly, 41 (4), 496-522. doi: 1598/RRQ.41.4.4

The Annie E. Casey Foundation. (2015). Kids Count Data Book. Baltimore, MD. Retrieved from http://www.aecf.org/resources/2015-kids-count-data-book/

U.S. Department of Education, National Center for Education Statistics, 1999, March. The Executive Summary of the 1998 National Assessment of Educational Progress Reading Report Card for the Nation, NCES 1999-50, Washington, DC.

Wolf, M. (2017). New research on an old problem: A brief history of fluency. Retrieved July 5, 2017 from https://www.scholastic.com/teachers/articles/teaching-content/new-research-old-problem-brief-history-fluency/ 